
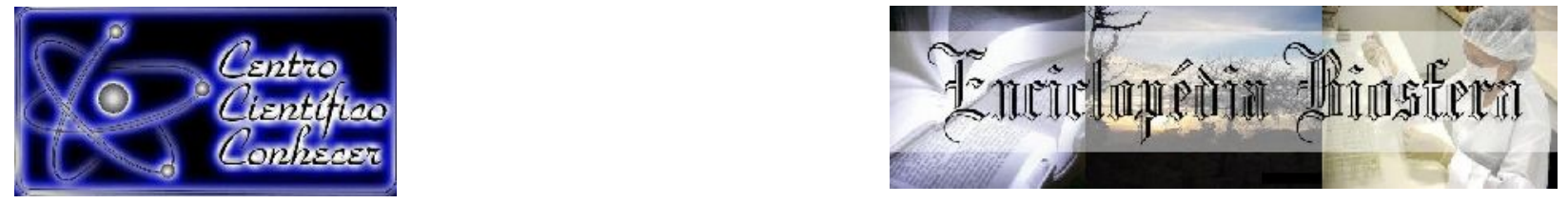

\title{
ATUAÇÃO DOS ENFERMEIROS NA PREVENÇÃO E ACOMPANHAMENTO DA DEPRESSÃO PUERPERAL
}

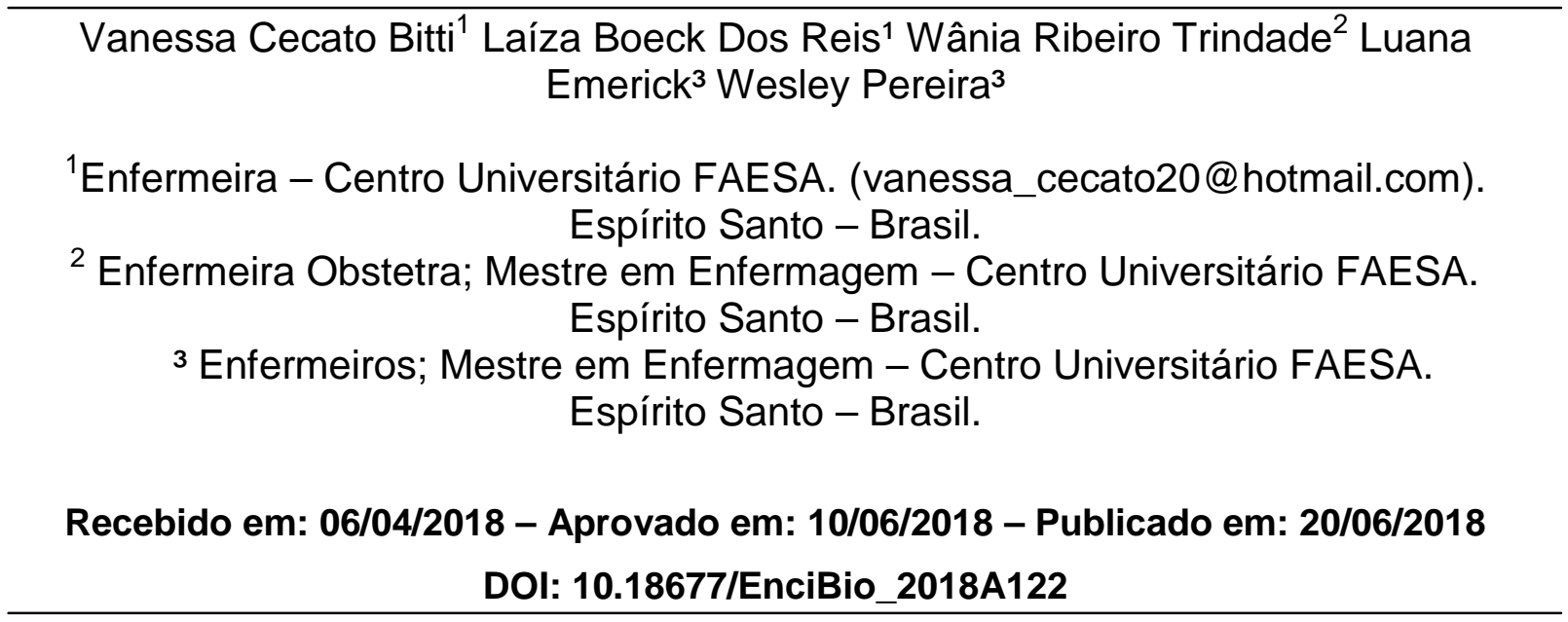

\section{RESUMO}

A depressão puerperal é caracterizada pela intensidade dos sintomas humorais provocados no período pós parto. A atenção e cuidado apresentado pela equipe de enfermagem e pela família são de grande importância para o desempenho no reconhecimento da doença. A pesquisa é de abordagem qualitativa de caráter exploratório. Teve como objetivo identificar o conhecimento e atuação dos enfermeiros relacionados à prevenção da depressão puerperal e sua detecção precoce. A coleta de dados foi realizada, por meio de entrevista semiestruturada, no período de junho a julho de 2017 em uma maternidade de Cariacica-ES. A análise dos dados foi feita através do conteúdo de Bardin. Os resultados apontaram que as enfermeiras possuem um conceito favorável sobre a doença com limitação de conhecimento sobre os sinais e sintomas. As dificuldades no reconhecimento da doença dão-se mais em relação à sobrecarga de trabalho, com pouco tempo para a assistência. Porém, falta o apoio de um profissional da área da psicologia. Sugerese reestruturação do trabalho, apoio da educação permanente, mais pesquisas sobre o tema e a realização do processo de enfermagem.

PALAVRAS CHAVE: Enfermagem, Depressão Puerperal, Cuidados de Enfermagem.

\section{NURSES 'ACTIVITIES IN THE PREVENTION AND MONITORING OF PUERPERAL DEPRESSION}

Postpartum depression is characterized by the magnitude of mood symptoms that occur in the postpartum period. The attention provided by the nursing team and patient's family is extremely important to recognize the disorder. This research has a qualitative approach and exploratory feature. The main goal was to identify the 
nurses' ability to acknowledge and avoid postpartum depression. The data were collected from a maternity hospital between June and July 2017. Nurses who work in this maternity in Cariacica- ES were submitted to a semi-structured interview. The data analysis was based on Bardin's content analysis. Results showed that nurses understand the disease, however, they have limited knowledge about signs and symptoms. This difficulty is due to a work overload that hinders health care. It still lacks a professional psychologist support. It is suggested a reconstruction of work, support for continuing education, additional studies about this subject and to perform the Nursing Process.

KEYWORDS: Nursing, Postpartum depression, Nursing care.

\section{INTRODUÇÃO}

Uma gravidez é marcada por várias alterações físicas e psicológicas. Durante a gestação ocorre uma série de transformações no organismo, aumentando as expectativas das mulheres sobre uma gravidez perfeita. Já no período puerperal, a decepção e o medo de nunca corresponder às perspectivas do papel materno, gera insegurança na mulher que podem contribuir com o aparecimento de sintomas da depressão puerperal (AZEVEDO; ARRAIS, 2006, p.272).

$\mathrm{Na}$ fase puerperal, ocorre um estágio do ciclo gravídico, onde começa depois da dequitação da placenta e finaliza até a reação do organismo materno, sendo assim, acontecem inúmeras reações hormonal e psicológica que ocorre após seis semanas pós-parto (PEREIRA, 2014, p.35).

Um dos problemas que as mulheres estão propicias a desenvolver neste período é a depressão puerperal. Essa patologia prejudica o bem-estar da progenitora tanto quanto 0 crescimento da criança. Podem também ocorrer mudanças significativas na personalidade da puérpera que será afetada pelo novo papel a ser desempenhado como mãe. No surgimento das reações que decorrem do período pós-parto, manifestam-se sinais semelhantes de um quadro depressivo: tristeza, prostração persistente, sensação de culpa, insônia, ideação suicida, receio de machucar o filho, hiporexia, anorgasmia, perda do nível de funcionalidade mental e aparecimento de ideias obsessivas (VALENÇA, 2010, p.130).

Os critérios de classificação para o diagnóstico de depressão puerperal são os sinais e sintomas que podem variar de intensidade, e muitas vezes acabam sendo negligenciados pela família, por profissionais sem muito conhecimento e também pela própria puérpera. Atualmente, a mídia vem desmistificando essa problemática na sociedade, e alerta a importância de uma atenção para o problema (CRUZ, 2005, p.182).

A melancolia da maternidade é conhecida como "Baby blues" que é um distúrbio leve e transitório e pode ocorre a partir da primeira semana após o parto, afetando a funcionalidade da mãe e colocando em risco a saúde e bem estar da puérpera, sendo considerado um fator de risco para a saúde do bebê. $O$ índice de acometimento do baby blues é mais alto devido as grandes mudanças fisiológica do puerpério e as quedas bruscas das alterações hormonais. A depressão está relacionada pela intensidade dos sintomas, sendo caracterizada por transtorno psíquico moderado a severo com início insidioso, podendo ser manifestado por volta da segunda ou terceira semana de puerpério. Já a psicose puerperal é um distúrbio de humor psicótico que pode apresentar perturbações mais graves podendo ocorrer na terceira semana de puerpério (COUTINHO, 2008; SILVA, 2006) 
Nas pesquisas sobre depressão puerperal, o percentil brasileiro da doença chega a 30 a $40 \%$ das mulheres. Ao comparar com os outros países a prevalência da doença se assimila com o percentil brasileiro, como exemplo: Itália (38,1\%), Chile $(37,4 \%)$, África do Sul $(36,5 \%)$, Índia $(32,4 \%)$ e Turquia $(29,8 \%)$ por LOBATO et al. (2011, p.376).

Dados de um estudo realizado na Unidade de Saúde de Maruípe, bairro pertencente ao município de Vitória-ES, as mulheres foram avaliadas pela Escala de Depressão Pós Parto Edimburgo, mostrou que os sinais e sintomas mais encontrados neste caso foram à tristeza maternal, e não a depressão pós parto, chegando essa a um percentual de 39,4\% por RUSCHI et al. (2007, p.279).

O vínculo entre o profissional e a puérpera é de grande importância devido à atuação dos enfermeiros no trabalho humanístico e na escuta qualificada das puérperas por FRANCISQUINI et al. (2011, p.744).

As visitas foram realizadas na maternidade durante a disciplina de Saúde da Mulher II do curso de Enfermagem-FAESA, onde foram observadas dificuldades no reconhecimento da depressão puerperal, problema tão importante que requer uma atenção especial. Diante disso, surgiram as seguintes questões norteadoras: Os enfermeiros estão sabendo reconhecer sinais e sintomas da depressão puerperal? Quais as dificuldades encontradas pelos enfermeiros para identificar os sinais e sintomas da depressão puerperal? Quais os cuidados de enfermagem utilizados nos casos de depressão puerperal?

Diante do exposto o objetivo principal desse estudo foi identificar o conhecimento e atuação dos enfermeiros relacionados à prevenção da depressão puerperal e sua detecção inicial.

Com este estudo, pretende-se agregar ao enfermeiro habilidades que proporcionarão um ambiente favorável para mudança profissional, de modo a desempenhar um papel de facilitador na promoção de saúde durante a assistência da puérpera.

\section{MATERIAL E MÉTODOS}

Trata-se de uma pesquisa de abordagem qualitativa de caráter exploratória realizada em uma maternidade pública que atende gestantes de risco habitual, localizada no município de Cariacica-ES. Para participar da pesquisa foram convidadas nove enfermeiras que atuam na referida maternidade onde foi realizada a pesquisa. Vale ressaltar que as nove enfermeiras compõem o quadro completo de enfermeiras da maternidade, o que justifica a escolha do quantitativo.

A coleta de dados foi realizada após a autorização e aprovação do Comitê de Ética em Pesquisa do Centro Universitário FAESA, sendo aprovado conforme também prevê a Resolução ํㅜ 466/12 do Conselho Nacional de Saúde (CNS), sob CAAE: 67250717.1.0000.5059 (BRASIL, 2012).

A técnica utilizada para coleta de dados foi uma entrevista semiestruturada individual, realizadas no período de junho a julho de 2017. Antes das entrevistas, as enfermeiras assinaram o Termo de Consentimento Livre e Esclarecido (TCLE) como garantia de uma das questões éticas e legais dessa pesquisa. As enfermeiras foram identificadas na análise com numeração de acordo com a ordem em que as entrevistas foram realizadas. Antes da coleta de dados, o local da pesquisa também foi autorizado pela Comissão de ética do Centro de Ensino e Aperfeiçoamento em pesquisa (CEAP) responsável por pesquisas realizadas na maternidade.

O método utilizado para a análise foi à Teoria de Bardin, que objetiva uma reflexão sobre a análise de conteúdo utilizado nas pesquisas qualitativas, capaz de 
incorporar o significado e a intencionalidade dos atos relacionados às estruturas sociais nas suas transformações, como construções humanas significativas (CAVALCANTE; CALIXTO; PINHEIRO, 2014, p.14).

Após a leitura das entrevistas, optou-se por construir a análise em três categorias temáticas: $O$ conhecimento sobre a depressão puerperal, Atuação do enfermeiro na depressão puerperal e Dificuldade da assistência de enfermagem em casos de depressão puerperal.

\section{RESULTADOS E DISCUSSÃO}

\section{CARACTERIZAÇÃO DO SUJEITO DA PESQUISA}

A tabela 1 mostra a caracterização das enfermeiras entrevistadas.

Tabela 1. Caracterização das entrevistadas

\begin{tabular}{lllc}
\hline Variáveis & Fator Avaliativo & $\mathbf{N}$ & $\%$ \\
\hline \multirow{2}{*}{ Gênero } & Feminino & 9 & $100 \%$ \\
& Masculino & 0 & $0 \%$ \\
\hline \multirow{2}{*}{ Idade } & $25-30$ anos & 4 & $44,44 \%$ \\
& $30-35$ anos & 2 & $22,22 \%$ \\
& $40-45$ anos & 1 & $11,11 \%$ \\
& $45-50$ anos & 1 & $11,11 \%$ \\
Tempo de & $60-65$ anos & 1 & $11,11 \%$ \\
Formação & $1-5$ anos & 2 & $22,22 \%$ \\
& $10-15$ anos & 4 & $44,44 \%$ \\
Mais de um & $15-20$ anos & 2 & $22,22 \%$ \\
Emprego & Sim & 1 & $11,11 \%$ \\
\hline \multirow{2}{*}{ Quantidade de } & 1 Emprego & 3 & $33,33 \%$ \\
Emprego & 2 Empregos & 6 & $66,67 \%$ \\
\hline Especialização & 3 Empregos & 6 & $66,67 \%$ \\
em Enfermagem & Sim & 3 & $33,33 \%$ \\
Obstétrica & Não & 0 & $0 \%$ \\
\hline
\end{tabular}

Observa-se que $100 \%$ dos profissionais entrevistados são do sexo feminino, com maior percentual entre 25 a 30 anos de idade.

Em relação ao tempo de formação, o percentual foi de $44,44 \%$ para o período de cinco a 10 anos. Apenas duas enfermeiras (22,22 \%), possuem menos de cinco anos de atuação profissional. Esse dado é importante, pois evidencia que a maioria das enfermeiras possui maior tempo de formação profissional, teoricamente apresentam maior experiência na área e estão mais habilitadas em conhecer melhor os sinais e sintomas das doenças. Entre as entrevistadas apenas quatro estão concluindo a pós graduação em Enfermagem Obstétrica.

Quando questionado sobre outro emprego a maioria está em dedicação apenas a maternidade onde foi realizada a pesquisa. 


\title{
O CONHECIMENTO SOBRE A DEPRESSÃO PUERPERAL
}

O período puerperal é uma fase onde acontecem inúmeras mudanças que precisam ser assistidas de perto por profissionais qualificados para que não ocorra um quadro depressivo. No início das duas primeiras semanas após o parto, pode ocorrer a tristeza materna que é um transtorno autolimitado. Ele é considerado um fator de risco para depressão puerperal, quando apresentado no primeiro ano após o parto. Segundo Ruschi et al. (2007, p.275), o público dominante desta estatística são as mulheres que passam por situações marcantes em suas vidas.

A situação existencial apresentada pela mulher desestabilizada influencia no desenvolvimento do quadro depressivo, como por exemplo, nos casos de gravidez não desejada, gravidez repudiada por familiares, carência social e outros fatores capazes de desestruturar emocionalmente a relação entre a paciente e sua gestação. Somam-se a isso os fatores hormonais e hereditários que também podem estar envolvidos por FREITAS et al. (2014, p.1207).

\begin{abstract}
A experiência de gerar, parir e cuidar de um filho pode dar a mulher uma nova dimensão de vida e contribuir para o crescimento emocional e pessoal da mulher. Porém, ao mesmo tempo, pode causar desorganização interna, ruptura de vínculos e de papéis e até resultar em quadros de depressão puerperal por SOUSA DA SILVA et al. (2010, p.415).
\end{abstract}

Para avaliar o conhecimento das enfermeiras que participaram da pesquisa sobre depressão puerperal, foi perguntado inicialmente o que elas conheciam sobre o assunto. Através desse questionamento, uma das enfermeiras respondeu que:

\footnotetext{
"Depressão puerperal é a depressão que acontece depois do parto. Depois que a mulher tem o bebê, e geralmente ela fica mais introvertida. Mostra pouco interesse em cuidar do bebê, e precisa de um acompanhamento" (Enfermeira 4).
}

A enfermeira 4 mostra uma boa percepção sobre depressão puerperal. Contextualizando o relato dessa enfermeira e a citação do autor Freitas et al. (2014, p.1207) e Sousa da Silva et al. (2010, p.415), a importância e a influência da experiência de gerar uma vida traz grandes emoções no decorrer da gestação que pode proporcionar uma desorganização mental. Para prevenir isso, a gestante deve ser acompanhada ao longo da gestação e no pré-natal ser avaliada quanto à possibilidade de desenvolver uma depressão puerperal. Ressalta-se que existe uma labilidade dos hormônios durante a gestação e após o parto, o que facilitaria o aparecimento do problema nessa fase. Logo após o parto se o problema for reconhecido precocemente, a melhora poderá ser mais rápida.

Greinert et al. (2005, p.27), também referem que a depressão pode manifestar-se em mulheres no período pós-parto, devido a eventos naturais que levam à predisposição psicológica e psicossocial, que sensibiliza a mulher, deixando-a fragilizada.

Segundo Coutinho (2008, p.768), a depressão durante a fase puerperal é definida pela intensidade dos sintomas humorais relacionados à fase após o nascimento da criança. Inicialmente aparece a melancolia da maternidade, conhecida como "Baby blues" e pode levar a desenvolver uma psicose puerperal, não adquirindo necessariamente uma depressão pós parto.

O significado da palavra depressão de acordo com dicionário online (2017) conceitua-se como um distúrbio psíquico que se exprime por períodos duráveis e recorrentes de disforia, concomitantemente com problemas reais ou imaginários ou 
com experiências momentâneas de sofrimento, podendo ser acompanhado de perturbações do pensamento, da ação e de um grande número de sintomas psiquiátricos (MICHAELIS, 2017).

\section{"É um estado psíquico em que a mulher rejeita o bebê e envolve alterações hormonais." (Enfermeira 1)}

A descrição do autor Coutinho (2008, p.768) e o conceito de depressão do dicionário vem ao encontro com o conceito da enfermeira 1, pois identifica que a depressão é caracterizada por um estado psíquico de intensidade dos sintomas humorais, decorrente de problemas ou experiências negativas.

Dentre os resultados desse primeiro questionamento também foi identificado um nível de conhecimento diminuído sobre a depressão puerperal entre as enfermeiras:

\footnotetext{
"Eu não conheço muito, mas eu sei que ela existe, e que acomete algumas mulheres no puerpério, mas eu não sei em relação à gravidade, essas coisas." (Enfermeira 8)
}

Segundo o comentário da enfermeira 8, sabe-se que a depressão puerperal existe, mas não consegue correlacionar com fatores que possam gerar maiores agravos à puérpera. Quanto aos sinais e sintomas da doença, à depressão puerperal inclui irritabilidade, choro frequente, sentimento de desamparo e desesperança, falta de incentivo motivacional, renúncia sexual, fraqueza, insônia e insegurança de lidar com a nova experiência psicossomática. A progenitora pode apresentar sintomas como cefaleia, lombalgia, erupções vaginais e dor abdominal, sem causa original aparente no decorrer da doença por COSTA TOLENTINO et al.(2016, p.61). Outras manifestações podem ser exemplificadas na fala da Enfermeira 9, a seguir:

\footnotetext{
"Geralmente a puérpera não quer ter contato com o bebê. Ela dificilmente põe o bebê pra amamentar por conta própria. Ela não fala muito. A gente tenta fazer as perguntas e ela não responde muito bem. Quando responde, responde com pouca cooperação. Os primeiros sinais são esses, tem os sinais mais profundos, mas na assistência que a gente tem aqui que às vezes o período é curto (...) os que agente tem são esses, os principais que eu consigo avaliar." (Enfermeira 9)

"O humor da puérpera modifica, tem rejeição da criança, não adere ao aleitamento materno. Até mesmo não aceita algum tipo de visita. $O$ auto cuidado fica deficiente" (Enfermeira 5)
}

Diante do relato da enfermeira 9, pode-se inferir que possui uma boa percepção sobre os sinais e sintomas da depressão puerperal, quando exemplifica o distanciamento, principalmente do filho recém-nascido, a apatia, a baixa verbalização e a falta de cooperação. Apesar do período curto de assistência, como foi atribuído na fala da enfermeira 9, no geral todas as participantes da pesquisa citaram corretamente os sinais e sintomas durante as entrevistas.

Quanto à primeira parte da pesquisa que foi avaliar o conhecimento das enfermeiras sobre a depressão puerperal, ainda existem aquelas que possuem dificuldade em conceituar o problema, mas identificam, mesmo que numa assistência limitada, os sinais e sintomas da doença. Nota-se uma importância de 
que haja uma maior dedicação à prática da promoção, prevenção, recuperação e reabilitação da saúde das mulheres assistidas pelas enfermeiras.

\title{
ATUAÇÃO DO ENFERMEIRO NA DEPRESSÃO PUERPERAL
}

A assistência de enfermagem deve estar pautada em alguns pilares que fazem com que o vínculo entre profissionais e gestantes se tornem indispensáveis para uma atuação qualificada e fidedigna. A sensibilidade da ausculta e a atuação é o que determina uma relação bem definida e confiante FRANCISQUINI et al. (2011, p.744).

Nessa pesquisa as enfermeiras também foram questionadas sobre as medidas realizadas para melhorar a assistência das puérperas com suspeita de depressão puerperal. Sobre esse assunto, alguns depoimentos das entrevistadas podem ser exemplificados:

\begin{abstract}
"E a gente conta também com o serviço de outro Hospital. A presença da pastora. Tem uma pastora que está presente nesse momento. Como não tem psicólogo, a gente faz uma rede. Então juntamos enfermagem, serviço social, com o pastoril lá de outro hospital e a gente tenta estar ajudando". (Enfermeira 6)

"Conversar com as pacientes. Orientação. Dando atenção que ela necessita. Tentando tranquilizar. Mostrando pra ela a necessidade que ela tem de estar cuidado do bebê, porque o bebê necessita daquele contato com a mãe, da presença da mãe, do leite da mãe que é de onde ele se alimenta". (Enfermeira 3)

"Acolher ela de tudo quanto é forma, pra que ela consiga perceber que pelo menos o bebê necessita dela, da ajuda dela, do alimento dela, pra ela esteja pelo menos fazendo essa parte, e o resto a gente vai trabalhando aos poucos, apoiando (...) é um trabalho bem ardor, por que a depressão não sai daqui pra li, ela se prolonga então a gente tem que estar junto, apoiando mesmo". (Enfermeira 3)
\end{abstract}

O autor Francisquini et al. (2011, p.744), cita que o vínculo entre o profissional e a puérpera é de grande importância devido a atuação dos enfermeiros no trabalho humanístico e na escuta qualificada das puérperas. Sendo assim, por mais que a enfermagem esteja envolvida com outras ações assistenciais ou administrativas, torna-se imprescindível o estabelecimento de vínculo com as mulheres, pois só assim é capaz de identificar as possibilidades de mudança de temperamento e humor.

Em suma, observa-se nas falas das entrevistadas que no geral elas buscam contribuir na solução do problema apresentado pelas puérperas no que se refere a suspeita da depressão puerperal, pois citam a existência de uma rede de apoio com a participação do serviço social e a pastoral. Em contrapartida, algumas entrevistadas e sentem sobrecarregadas, pois precisam resolver problemas burocráticos e assistenciais ao mesmo tempo em um curto período. Citam que o quadro de funcionárias da maternidade é pequeno e faltam profissionais, com, por exemplo, o psicólogo.

"A gente não tem um psicólogo, então é a gente mesmo que tem que fazer esse trabalho". (Enfermeira 3) 
"Eu acho sinceramente que o enfermeiro, pelo menos dentro da nossa instituição tem é a falta de tempo, por que o enfermeiro ele faz tudo." (Enfermeira 05)

“(...) O enfermeiro tem muitas atribuições, ainda mais com todos esses protocolos que a gente tem (...) o enfermeiro hoje mexe muito com papel, e tem que prestar conta de muito papel, então àquela parte do cuidar $100 \%$ fica prejudicado." (Enfermeira 5)

Vale ressaltar que o grupo hospitalar na qual a maternidade faz parte, são em cidades diferentes, porém próximas. O psicólogo fica em outra unidade hospitalar e a maternidade não tem esse profissional. Nesse ínterim, para o tratamento da depressão puerperal, a puérpera precisaria se deslocar até outra cidade o que dificulta o tratamento. No entanto, os profissionais envolvidos é a equipe de enfermagem e do serviço social ajudam e dão apoio de imediato, quem fecha o diagnostico é o médico. Caso a puérpera necessita do psicólogo, será encaminhada para outro hospital dependendo da necessidade e do caso.

$\mathrm{Na}$ atuação da enfermagem, os principais sinais e sintomas relacionados com a depressão puerperal podem ser percebidos logo no início da doença, sendo possível avaliar o bem estar físico do binômio mãe e filho no parto e puerpério. A enfermagem tem um domínio técnico científico e autonomia para intervir nos problemas enfrentados com a depressão puerperal e minimizando os riscos de um maior problema à parturiente, caso seja percebido no início (JÚNIOR, 2011, p.517).

As teorias de enfermagem mostram como podemos contextualizar a depressão puerperal através da Teoria do Déficit do Autocuidado de autoria de Dorothea Orem, a qual é constituída por três conceitos teóricos: autocuidado, déficit de autocuidado e sistema de enfermagem. $O$ autocuidado constitui na prática de atividades que os pacientes desempenham para seu próprio beneficio com o propósito de preservar a vida saudável. Com essas ações é possível proporcionar a integridade estrutural e o desenvolvimento humano por BUB et al.(2006, p. 155).

A aplicação da teoria de Dorothea Orem fará com que os pacientes melhorem a qualidade de vida, aumentando o vinculo com o $\mathrm{RN}$ e diminuindo o índice da depressão puerperal na instituição, sem interferir nas obrigações rotineiras das enfermeiras.

O autor Júnior (2011, p.517) defende que a enfermagem tem total capacidade em ajudar e orientar na minimização dos sinais e sintomas caso seja percebido a doença no início, podendo trazer um bem estar físico no binômio mãe e filho. $O$ autor Vitor (2010, p.613) mostra que através da utilização dos princípios da Teoria do Déficit do Autocuidado de Dorothea Orem, o cuidado de Enfermagem busca auxiliar e ensinar a puérpera a exercer atividades simples e promover autonomia na realização do cuidado do bebê.

No período pós parto, o tipo e a natureza do suporte fornecido à mulher é o que determina uma melhor adaptação e alcance do papel materno. Nesta fase, o enfermeiro pode prestar decisiva colaboração, pois ao conhecer a situação vivenciada, este profissional contribui com a puérpera para que se mantenha tranquila e consiga se readaptar melhor às suas necessidades, favorecendo uma educação saudável no período da maternidade, entre mãe e filho (SILVA, 2006, p. 412).

Somente profissionais de saúde não são suficientes para contribuir com adaptação da puérpera a esse novo momento da sua vida. Dentro da rede de apoio, 
torna-se imprescindível a participação familiar, como exemplificado nos relatos a seguir, proferidos pelas depoentes:

\begin{abstract}
"A família precisa entender o que está passando com a puérpera, por que essa questão de depressão puerperal, eu não vejo como uma situação muito comum e não é tá (...). A gente tem poucas situações aqui na maternidade. A gente tem que primeiro estar conversando com a família, deixar a família antenada pra saber o que vem a ser uma depressão puerperal, pra família também está podendo dar apoio pra essa puérpera, por que a nossa clientela é um pouco deficiente de conhecimento". (Enfermeira 6)

"Então pra família poder estar ajudando junto com a gente, ela tem que saber o que está acontecendo, porque se não colocarmos essa família ciente da situação eles podem achar que a paciente está com frescura, vamos dizer assim."(...) "Isso é frescura, isso vai passar" (...) e acaba que a paciente se agrava mais, porque não vai ter um apoio, não vai ter ajuda que ela necessita e afundando mais nessa depressão e no caso ficando muito mais sério do que se pode esperar" (Enfermeira 6).
\end{abstract}

Segundo o autor Silva (2006, p. 412), o enfermeiro tem capacidade para auxiliar a puérpera e melhorar a adaptação do papel materno, fornecendo, incentivando e dando empoderamento a puérpera para a realização do cuidado com bebê. A enfermeira 6 , ressalta a importância da família em saber dos sinais e sintomas. A Enfermagem tem um papel importante em orientar a família no processo de aceitação da doença, para dar apoio e mantê-los unidos diante do problema. $\mathrm{O}$ suporte familiar é de extrema importância à puérpera nesta fase. Porém, surgiu também nos depoimentos limitações nesse suporte familiar, pois muitas famílias possuem pouco conhecimento, baixas condições financeiras e problemas familiares.

O enfermeiro tem total autonomia para orientar sobre a depressão puerperal, porém, no que se refere aos profissionais, Júnior (2009, p.523) aponta a necessidade do conhecimento específico que visam acoplar práticas e estratégia para cuidar desta problemática. Sendo necessária uma atenção especializada para enfrentar desafios sem perder a essência do papel da enfermagem.

Quanto ao papel do enfermeiro no reconhecimento das necessidades dos indivíduos que são acompanhados em sua assistência, baseado na lei 7.498 de 25 de junho de 1986, que dispõe sobre o exercício da enfermagem, decreta que o profissional de Enfermagem exerça suas atividades com competência para promoção da saúde, mantendo o estado da saúde ou melhorando a qualidade de vida do cliente. O enfermeiro deve buscar sempre aprimorar os conhecimentos para garantir uma assistência que seja diferenciada e qualificada para execução de tarefas não rotineiras do hospital (BRASIL, 1986).

\title{
DIFICULDADE DA ASSISTÊNCIA DE ENFERMAGEM EM CASOS DE DEPRESSÃO PUERPERAL
}

Os profissionais de saúde enfrentam tensões e estresse durante a jornada de trabalho excessiva, com número reduzido de profissionais, gerando um desgaste psicoemocional nas tarefas do ambiente hospitalar. É comum observar as equipes de enfermagem trabalhando em ambiente insalubre e, por estarem submetidos a 
condições de trabalho precárias, são expostas a situações nas quais a manutenção da saúde está prejudicada por QUIRINO et al. ( 2009, p.687).

O exemplo das dificuldades enfrentadas pelas enfermeiras, principalmente no que tange ao reconhecimento da depressão puerperal e a assistência de enfermagem podem ser observadas nos seguintes depoimentos:

\begin{abstract}
"Então, trabalhar com amor a gente trabalha, só que as vezes faltam pernas, a gente quer dar o nosso melhor, mas às vezes a gente não consegue porque a demanda de serviço é muito grande, às vezes no final do plantão a gente fala assim: a sensação que eu tive é que eu estava apagando incêndio, e não fiz o que tinha que fazer, não coloquei um bebê pra amamentar direito porque quando eu estava fazendo, fui chamada pra atender uma intercorrência no centro cirúrgico. A técnica me chamou para resolver coisas de prescrição. Então eu acho que o nosso desafio é esse, saber que a gente precisa fazer o nosso melhor, a nossa profissão é uma dádiva de Deus porque não é qualquer um que sabe cuidar das pessoas, mas a gente precisa que na nossa profissão as coisas melhorem pra gente. Voltando lá nos primórdios, que é o cuidar, hoje em dia a gente tem é papel pra preencher,então o objetivo maior, o foco maior do nosso trabalho vai ficando de lado..." (Enfermeira 5)
\end{abstract}

Analisando os relatos das enfermeiras da maternidade, foram destacados diversos problemas que interferem em uma assistência qualificada à puérpera. $O$ principal motivo é a falta de tempo e excesso de atividades, com isso a assistência se torna difícil.

Segundo o Conselho Federal de Enfermagem, o enfermeiro deve estar apto a exercer todas as atividades propostas a ele, sempre buscando conhecimento que é o fator principal para diferenciar um profissional (BRASIL, 1986). Além da falta de tempo e o excesso de responsabilidades que distanciam o enfermeiro do seu real objeto de trabalho, a falta de conhecimento por parte da enfermagem também foi citada.

"A depressão puerperal é caracterizados pelas alterações psicológica, muitos profissionais não tem tanto domínio do assunto". (Enfermeira 1)

Segundo o relato da enfermeira 1, há uma falta de conhecimento em relação há alguns profissionais de saúde, atrapalhando no desenvolvimento de uma atividade mais qualificada. Devido à falta de conhecimento, há uma necessidade de promoção da educação permanente, o que trará benefícios no reconhecimento da doença, assim como de outros problemas que acometem o ciclo gravídico puerperal.

Investir no reconhecimento e acompanhamento da depressão puerperal repercute positivamente no estabelecimento do vínculo entre mãe e filho e na prevenção de problemas futuros na vida da criança e posteriormente na vida adulta, pois, segundo Carlesso (2011), sofrimentos psíquicos vivenciados pelas mulheres anteriormente podem ocasionar problemas de apego ao bebê:

Há evidências de que falhas no cuidado inicial devido à negligência, abuso físico e/ou psicológico estão associadas a alterações no padrão de apego e no desenvolvimento motor e mental dos bebês (CARLESSO, 2011, p.1119).

Outra dificuldade em prestar assistência à mulher com depressão puerperal é que em muitas vezes, é necessário entrar no contexto familiar. Ou seja, entrar em assuntos íntimos ou delicados que em muitas situações são preferidos por deixar ENCICLOPÉDIA BIOSFERA, Centro Científico Conhecer - Goiânia, v.15 n.27; p.1433 
ocultos ou minimizados. A enfermagem também possui dificuldade ou despreparo em penetrar em assuntos frágeis, íntimos e delicados da vida das pessoas, mesmo que através da consulta de enfermagem isso faça parte do exercício da profissão.

"A gente conseguir entrar no contexto da família é muito difícil, você entra numa intimidade que não está acostumada, ninguém está acostumado com você ali no meio." (Enfermeira 9)

Através dos relatos das entrevistadas e a fala do autor Carlesso (2011, pag.1119), percebe-se que a negligência não afeta só a puérpera, mas influencia no comportamento e desenvolvimento dos bebês que passam por esse sofrimento. $O$ despreparo em lidar e reconhecer os sinais e sintomas da depressão puerperal pode ser negligenciado pelos profissionais de saúde e principalmente pela família. A doença pode ser vista como uma forma de chamar atenção.

\section{CONCLUSÕES}

Os resultados desse estudo possibilitaram identificar o conhecimento e atuação dos enfermeiros relacionados á prevenção da puerperal e sua detecção precoce na maternidade.

Em relação ao conhecimento das enfermeiras identificou-se que possuem uma boa percepção da doença, tanto do conceito, como dos sinais e sintomas, com algumas limitações nas falas. Acredita-se que o fato de algumas enfermeiras estarem cursando a Especialização em Enfermagem Obstétrica contribuirá ainda mais no reconhecimento da patologia e condução dos casos identificados de depressão puerperal.

Sugere-se que a implantação de educação permanente nos espaços de atuação da enfermagem, assim como as normas e rotinas, esteja alinhada de acordo com as características dos serviços que atendem mulheres, bebês e famílias. Orienta-se que haja uma melhor distribuição do número de profissionais e atribuições de enfermagem nos serviços, evitando assim a problemática constante relacionada à sobrecarga de trabalho, a assistência inadequada e com baixa qualidade.

Através desse estudo, observou-se o interesse das enfermeiras em orientar e colaborar para minimizar os sintomas da depressão puerperal, porém a rotina do enfermeiro é dividida em assistencial e muitas vezes administrativa, o que dificulta a implantação do processo de enfermagem que facilitaria a aproximação da enfermagem à clientela. As enfermeiras também se dividem em preenchimento dos dados, agendamento de exames, avaliações e protocolos a ser seguidos, aumentando a demanda de trabalho, o que dificulta na realização de uma melhor assistência.

Vale ressaltar que a Maternidade por ser de baixo risco, ou seja, recebe gestante que não apresentaram nenhum tipo de problema durante a gravidez, por exemplo: diabetes gestacional e urgências hipertensivas. Não possui muitos casos da doença, e os casos identificados são encaminhados para outras unidades para acompanhamento.

E espera-se contribuir com a equipe de saúde, puérperas e as famílias resgatando a essência maternal que muitas mães perdem ao vivenciar essa doença. Com a percepção inicial, espera-se diminuir 0 risco de futuras doenças desencadeadas por uma depressão puerperal não avaliada com antecedência. Trata- se de um estudo relevante, pois a relação do enfermeiro, puérpera e familiar 
durante a assistência obstétrica segura pode atingir os níveis de maior complexidade minimizado os riscos e agravos do surgimento da doença.

\section{REFERÊNCIAS}

AZEVEDO, K.R.; ARRAIS, A.R.; Alessandra, A.R. O mito da mãe exclusiva e seu impacto na depressão pós-parto. Psicologia: reflexão e crítica, v. 19, n. 2, p. 269276, 2006.

BRASIL. Conselho Nacional de Saúde. Resolução $n^{\circ} 466,2012$. Diretrizes e Normas regulamentadoras de pesquisa envolvendo seres humanos.

BRASIL. (25 de junho de 1986). LEI N.⒎498, DE 25 JUNHO DE 1986. Dispõe sobre a regulamentação do exercício da Enfermagem, p. 3. Disponível em: http://www.camara.gov.br/sileg/integras/377633.pdf > Acesso em: 23 out 2017.

BUB, M. B. C.; MEDRANO, C.; SILVA, C. D. D.; WINK, S.; LISS, P. E.; SANTOS, E. K. A. D. A noção de cuidado de si mesmo e o conceito de autocuidado na enfermagem. Texto Contexto Enferm, v. 15, p. 152-7, 2006.

CARLESSO, J. P. P.; DE SOUZA, A. P. R. DIALOGIA MÃE-FILHO EM CONTEXTOS DE DEPRESSÃO MATERNA: REVISÃO DE LITERATURA. Revista CEFAC, v. 13, n. 6, 2011.

CAVAlCANTE, R. B.; CALIXTO, P.; PINHEIRO, M. M. K. Analise de Conteúdo: considerações gerais, relações com a pergunta de pesquisa, possibilidades e limitações do método. Informação\& Sociedade, v. 24, n. 1, 2014.

COUTINHO, M. P. L.; SARAIVA E. R. A. Depressão pós-parto: considerações teóricas. Estudos e pesquisas em psicologia, v. 8, n. 3, p. 0-0, 2008.

DA COSTA TOLENTINO, E.; MAXIMINO, D. A. F. M.;DE SOUTO, C. G. V. Depressão Pós-Parto: conhecimento sobre os sinais e sintomas em puérperas. Revista Ciência e Saúde Nova Esperança 2016.

SOUSA DA SILVA, F. C.; MOURA DE ARAÚJO, T.; MOURA DE ARAÚJO, M. F.; DE LIMA CARVALHO, C. M.; ÁFIO CAETANO, J. Depressão pós-parto em puérperas: conhecendo interações entre mãe, filho e família. Acta paul enferm, v. 23, n. 3, p. 411-6, 2010.

DA SILVA CRUZ, E. B.; SIMÕES, G. L.; FAISAL-CURY, A. Rastreamento da depressão pós-parto em mulheres atendidas pelo Programa de Saúde da Família. Revista Brasileira Ginecologia Obstétrica, v. 27, n. 4, p. 181-8, 2005.

RODRIGUES DE FREITAS, D.; DARGAM GOMES VIEIRA, B.; HERDY ALVES, V.; PEREIRA RODRIGUES, D.; MORETT ROMANO LEÃO, D. C.; FERNANDES DO NASCIMENTO DA CRUZ, A. ALOJAMENTO CONJUNTO EM UM HOSPITAL UNIVERSITÁRIO: DEPRESSÃO PÓS-PARTO NA PERSPECTIVA DO ENFERMEIRO. REVISTA DE PESQUISA: CUIDADO e Fundamental, v. 6, n. 3, 2014. 
FRANCISQUINI, A. R.; HIGARASHI, I. H.; SERAFIM, D.; BERCINI, L. O. Orientações recebidas durante a gestação, parto e pós-parto por um grupo de puérperas. Ciência, Cuidado e Saúde, v. 9, n. 4, p. 743-751, 2011.

GREINERT, B. R. M.; MILANI, R. G. Depressão pós-parto: uma compreensão psicossocial. Psicologia: teoria e prática, v. 17, n. 1, p. 26-36, 2015.

JÚNIOR, H. P. D. O. S.; DE ARAÚJO SILVEIRA, M. D. F.; GUALDA, D. M. R. Depressão pós-parto: um problema latente. Revista Gaúcha de Enfermagem, v. 30, n. 3, p. 516, 2009.

LOBATO, G.; MORAES, C. L.; REICHENHEIM, M. E. Magnitude da depressão pósparto no Brasil: uma revisão sistemática. Revista Brasileira Maternidade Infantil 2011.

MICHAELIS. Dicionário Brasileiro da Língua Portuguesa. Online. Editora Melhoramento Ltda. 2017. Disponível em: http://michaelis.uol.com.br/modernoportugues/busca/portugues-brasileiro/depress\%C3\%A3o/ > Acesso em: 12 out 2017.

VALENÇA, C. N.; GERMANO, R. M. Prevenindo a depressão puerperal na estratégia saúde da família: ações do enfermeiro no pré-natal. Revista da Rede de Enfermagem do Nordeste, v. 11, n. 2, 2010.

PEREIRA, M. C.; GRADIM, C. V. C. Consulta puerperal: a visão do enfermeiro e da puérpera. Ciência, Cuidado e Saúde, v. 13, n. 1, p. 35-42, 2014.

QUIRINO, D. D.; COLLET, N. "Fácies" do trabalho de Enfermagem na assistência à criança hospitalizada. Revista Eletrônica de Enfermagem, v. 11, n. 3, 2009.

RUSCHI, G. E. C.; SUN, S. Y.; MATTAR, R.; CHAMBÔ FILHO, A.; ZANDONADE, E.; LIMA, V. J. D. Postpartum depression epidemiology in a Brazilian sample. Revista de Psiquiatria do Rio Grande do Sul, v. 29, n. 3, p. 274-280, 2007.

SILVA, E. T. D.; BOTTI, N. C. L. Depressão puerperal uma revisão de literatura. Revista Eletrônica de Enfermagem, v. 7, n. 2, 2006.

SOUSA DA SILVA, F. C.; MOURA DE ARAÚJO, T., MOURA DE ARAÚJO, M. F.; DE LIMA CARVALHO, C. M.; ÁFIO CAETANO, J. Depressão pós-parto em puérperas: conhecendo interações entre mãe, filho e família. Acta Paulista de Enfermagem, v. 23, n. 3, 2010. 